\title{
Towards an Eco-Efficient Development Strategy that Minimises the Risks Associated with the Location of Gas Stations in Human Settlements: A Fuzzy PROMETHEE Method
}

\author{
Samuel Batambock ${ }^{1,2}$, Innocent Ndoh Mbue ${ }^{1,2 *}$, Dieudonne Bitondo ${ }^{1,2}$ \\ ${ }^{1}$ Laboratoire de Recherche Energie, Matériaux, Modélisation et Méthode (E3M), Douala, Cameroon \\ ${ }^{2}$ Ecole Nationale Supérieure Polytechnique de Douala (ENSPD), Université de Douala, Douala, Cameroon \\ Email: *dndoh2009@gmail.com
}

How to cite this paper: Batambock, S., Ndoh Mbue, I. and Bitondo, D. (2022) Towards an Eco-Efficient Development Strategy that Minimises the Risks Associated with the Location of Gas Stations in Human Settlements: A Fuzzy PROMETHEE Method. World Journal of Engineering and Technology, 10, 119-137.

https://doi.org/10.4236/wjet.2022.101007

Received: January 16, 2022

Accepted: February 25, 2022

Published: February 28, 2022

Copyright $\odot 2022$ by author(s) and Scientific Research Publishing Inc. This work is licensed under the Creative Commons Attribution International License (CC BY 4.0).

http://creativecommons.org/licenses/by/4.0/

\begin{abstract}
Evaluating real world situations in risky environments based on various qualitative/quantitative criteria in order to suggest a strategy/policy among available options is one of the critical challenges in incident management. Such is the case when considering an eco-efficient development strategy that can minimize the risk associated with the location of gas stations in human settlements. Taking the Douala city of Cameroon as an example, four actions were evaluated, including the options of relocating the gas stations, putting in place of emergency response plan in gas stations, and relocation of households subject to a group of four criteria. Data were collected via personal communication with decision-makers using a five-point Likert scale. The market values of buildings subject to expropriation were estimated based on order No. 0082/Y. 15.1/MNUH/D of 20 November 1987 of the ministry of Housing and Urban Development, Cameroon. The financial costs incurred in establishing a gas station were an average value obtained from a sample of 80 gas stations randomly selected among those whose locations do not comply with existing regulations. These amounts were obtained from their financial records, while the value of putting in place an emergency action plan was obtained from the current market value of the equipment required. The algorithm of PROMETHEE under the usual criterion function was implemented. The results suggested that putting in place an emergency response plan could minimize relocation costs, maximize profits/welfare, and maximize environmental quality, and minimize social impacts, and was therefore considered as the most preferred alternative. Sensitivity analyses of results further confirmed that implementation of emergency response plan is the most preferred alter-
\end{abstract}


native.

\section{Keywords}

Eco-Efficient Development Strategy, PROMETHEE, Criteria, Alternatives

\section{Introduction}

Displacement and resettlement initiatives, which pose a significant threat to informal settlements, are frequently included in urban rehabilitation and resettlement strategies to prevent disasters in fast-growing cities in developing countries [1] In Africa, for example, recently accepted urban visions and development plans for "new cities" or "modern cities" [2] are centered on improving living conditions for the rapidly growing urban population and stimulating local businesses [3]. Humans and the environment are frequently given little or no attention, resulting in environmental devastation in human-inhabited ecosystems plagued by a mix of social and environmental problems. A key question now is, "In the antibiosis, 'human-gas stations', such as in the city of Douala-Cameroon, which sustainable development strategy can minimise the risks there from?"

Licensed by a competent government entity and equipped with traditional oil-storage reservoirs, gas stations are essential components of the downstream gas delivery system. The purpose of building and operating gas stations is to complete the cycle of petroleum product production for human consumption. Any errors or disasters at the stations might threaten years of research, drilling, extraction, refining, distribution, and other enterprises. These incidents have taken on new dimensions in recent years, with the potential to have long-term negative consequences for the environment and people. We are particularly vulnerable to a wide range of potentially hazardous or fatal substances [4]. Major sources of contamination to soil, air, subsoil, and surface water have been identified as leaks from liquid fuel tanks, processed chemicals, poisonous compounds, and diluted discharges.

Because of characteristics such as the high flammability of petroleum products, gas stations have received the most attention in recent years. We argue here that, in order to reduce the risk of environmental racism, a development strategy that protects both man and nature is required. This is a complex decision-making problem that has been linked for many years to the use of multicriteria decision-making methods (MCDM). These methods are classified as discrete multicriteria decision-making models because all of the alternatives $\left(a_{1}, a_{2}, \ldots, a_{m}\right)$ and criteria $\left(f_{1}, f_{2}, \ldots, f_{n}\right)$ are known. The decision-maker establishes preferences based on aspiration levels or requirements, as well as criteria weights [5]. Decision-making problems can include various objectives: finding the best alternative, separating the alternatives into groups of acceptable and unacceptable or good/bad alternatives; dominated and non-dominated, finding clusters with similar or indifferent alternatives, or creating an order of alternatives [6]. 
Multiple criteria decision-making (MCDM) has proven to be an extremely useful tool for making effective decisions in a variety of fields, including but not limited to water management [7], waste management [8], industries [9], business and finance [10], medical and health sector [11], environmental management [12]. Many researchers used MCDM techniques to make strategic decisions in a variety of fields. AHP [13] [14], PROMETHEE [15] [16], Technique of Order Preference by Similarity to Ideal Solution (TOPSIS) [17], Elimination and Choice Translating REalite (ELECTRE) [18].

Because of its capacity to outrank alternatives and its availability in numerous versions, the PROMETHEE approach has been widely employed in a variety of applications, including but not limited to the identification and evaluation of alternative pipeline routes for transporting oil and gas to the world market, achieving lean attributes in the automotive industry [19], and recently, [20] combined the PROMETHEE and multi-criteria analysis to participate in the renewable energy sources assessment. The biggest difference between PROMETHEE and other MCDM methods is that it is well adapted to decision problems where a finite set of alternatives is to be outranked subject to multiple conflicting criteria [21].

However, there appears to be a paucity of literature with regard to the application of the PROMETHEE in development planning in human-inhabited industrial ecosystems. A key question is, "which eco-efficient development strategy could be adopted to minimize the social, economic, and environmental risks to humans and social infrastructure in human-inhabited ecosystems: do nothing, or emergency response plan, or relocate the population, or relocate gas stations?" More specifically, the research aims to:

1) Use the PROMETHEE I criterion for providing a complete ranking of selected eco-efficient development strategies in human inhabited ecosystems, taking the Douala city of Cameroon as an example.

2) Check the consistency of the complete ranking in selecting an eco-efficient development strategy using two types of preference functions.

3) Propose the most eco-efficient development strategy under the given scenario.

As earlier indicated, PROMETHEE method was selected because of its capacity to outrank alternatives and its availability in numerous versions, and also because of its wide range of applications. Douala was an appropriate case study because it is very common to find gas stations in the city located in regions of human housing and social infrastructure. Future planners and decision-makers will need this information in order to design and implement activities that will have the least detrimental impact on affected families and gas stations.

\section{Materials and Methods}

\subsection{Sampling}

In a previous research [22], gas stations were classified into different risk catego- 
ries (Low, Medium, and High), based on well-defined criteria. From the list of the gas stations posing high risk to the environment, the BOCOM gas station, of the Douala $5^{\text {th }}$ district and its environs was selected for evaluation. The district which hosts the gas station is characterized by anarchic urbanization including constructions of several levels of a variety of standings. Bocom Bepanda station is built on land with a total area of $1350 \mathrm{~m}^{2}$, stores hydrocarbon products like any other standard gas station in the country, and is surrounded by some 488 households, several schools, hospitals, markets, and other social infrastructures.

\subsection{Data Collection}

Data collection took place in April 2021. We first defined an exposure perimeter to the fire risk to which populations living near service stations $(100 \mathrm{~m})$ are exposed. The following assessments were made:

- The cost of relocating the gas station to a less risk-prone area.

- The cost of relocating the neighbouring population and social infrastructures (schools, hospitals, ...).

- The socio-economic and environmental impacts of relocation were also evaluated.

- Finally, the cost of putting in place an emergency response plan, like the impacts of "doing nothing" was also evaluated.

The market value of buildings subject to expropriation was calculated on the basis of Order No. 0082/Y. 15.1/MNUH/D of 20 November 1987. The financial costs incurred in establishing a gas station were an average obtained from a sample of 80 gas stations selected from gas stations whose locations are not in compliance with existing regulations [22]. These amounts were obtained from their financial records, while the value of putting in place an emergency action plan was obtained from the current market value of the equipment required.

\subsection{Linguistic Data Collection}

Data were collected through focus group interviews with experts/decision-makers in the city of Douala. The expert group was asked to rate the criteria using an impact scale with values of 1 to 5 (Table 1 ) to assess relative preferences for two items.

In all, a group of five experts (E1, E2, E3, E4, E5), drawn from the city council,

Table 1. Five-point Likert scale and its description.

\begin{tabular}{cc}
\hline Scale & Weight of importance \\
\hline 1 & Very High \\
2 & High \\
3 & Moderate \\
4 & Low \\
5 & Very Low \\
\hline
\end{tabular}


the University of Douala, the ministry of the environment and nature protection, the ministry of urban planning, and then the ministry of territorial administration was requested to rank and evaluate four alternatives (A1, A2, A3, A4) based on the four criteria (C1, C2, C3, C4). Here is an example of a questionnaire for experts regarding the overall objective".

- With respect to the overall goal "Selection of the best sustainable development strategy".

- Q1. How important is the cost criteria (C1) when it is compared to social impact $(\mathrm{C} 2)$ ?

- Q2. How important is cost criteria (C1) when it is compared to economic impact (C3)?

- Q3. How important is the cost criterion (C1) when compared to Environmental impact (C4)?

- Q4. How important is $\mathrm{C} 2$ when it is compared to $\mathrm{C} 3$ ?

- Q5. How important is $\mathrm{C} 2$ when it is compared to C4?

- Q6. How important C3 when it is compared to C4?

\subsection{Criteria and Alternatives}

Four criteria were chosen including the cost of relocations (C1), social impact (C2), Economic impact (C3), and Environmental impact (C4). Four alternatives are denoted by A1 ("Do nothing"), A2 (Relocation of inhabitants, A3 (Relocation of gas stations, and A4 (Putting in place an emergency response plan (A4). The framework applied to green supplier selection is presented in Figure 1.

\subsection{Data Analysis}

The PROMETHEE methodology (Figure 2) was employed.

The computational procedures of PROMETHEE need several steps, and this

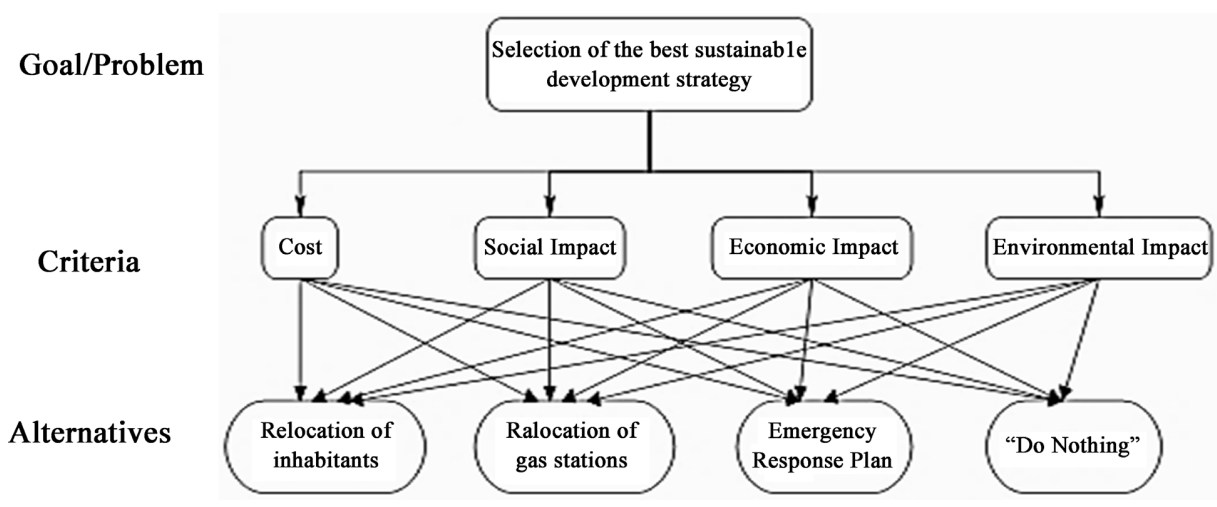

Figure 1. Framework for the selection of the best alternative.

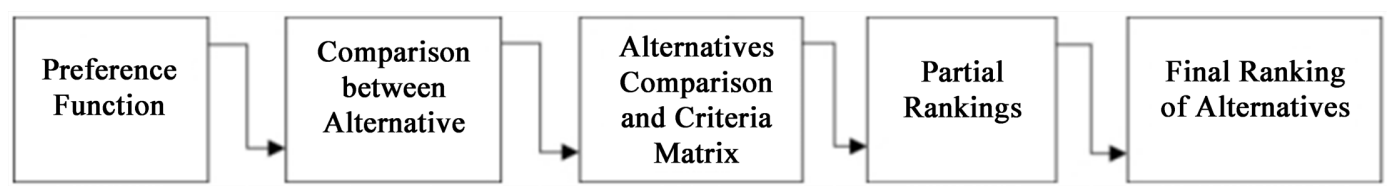

Figure 2. PROMETHEE methodology [23]. 
paper has summarized seven steps based on the works of [23].

Step 1. Determine the criteria $(j=1, \cdots, k)$ and the set of possible alternatives in a decision problem. These are used to create an $m \times n$ evaluation (decision) matrix (1)

$$
\left[X_{i j}\right]_{m n}=\left[\begin{array}{ccc}
x_{11} & \cdots & x_{1 n} \\
\vdots & \ddots & \vdots \\
x_{m 1} & \cdots & x_{m n}
\end{array}\right]
$$

Step 2. Determine the weight $w_{j}$ of the criteria. It shows the relative importance of each of the criteria. The weights show the relative importance of each of the criteria and note according to (2):

$$
\sum_{j=1}^{k} w_{j}=1
$$

Step 3. Normalize the decision matrix to range 0 - 1 according to (3)

$$
R_{i j}=\left\{\begin{array}{l}
\frac{\left[x_{i j}-\min \left(x_{i j}\right)\right]}{\left[\max \left(x_{i j}\right)-\min \left(x_{i j}\right)\right]}, \\
\frac{\left[\max \left(x_{i j}\right)-x_{i j}\right]}{\left[\max \left(x_{i j}\right)-\min \left(x_{i j}\right)\right]},
\end{array}\right.
$$

where:

$x_{i j}=$ is evaluation values provided by decision-makers, with $i=1, \cdots, n$, and $j=1, \cdots, m$, and numbers of criteria.

Step 4 . Determination of deviation by pairwise comparison (4)

$$
d_{j}(a, b)=g_{j}(a)-g_{j}(b)
$$

where, $d_{j}(a, b)$ denotes the difference between the evaluations of $a$ and $b$ on each criterion.

Step 5. Define the preference function (5)

$$
P_{j}(a, b)=F_{j}\left[d_{j}(a, b)\right], \forall a, b \in A
$$

where:

$$
P_{j}(a, b)=g_{j}(a)-g_{j}(b)
$$

and for which:

$$
0 \leq P_{j}(a, b) \leq 1
$$

The smaller number of the functions denotes the indifference of the decision-maker. On the contrary, the closer to 1 indicates greater the preference. In case of a criterion to be maximised, this function is giving the preference of over for observed deviations between their evaluations on criterion, $g_{j}($.$) . For crite-$ ria to be minimised, the preference function should be reversed or alternatively given by (7):

$$
P_{j}(a, b)=F_{j}\left[-d_{j}(a, b)\right], \forall a, b \in A
$$

The pair $\left\{g_{j}(.) ; P_{j}(a, b)\right\}$, is the generalised criterion associated to criterion 
$g_{j}($.$) . Such a generalised criterion has to be defined for each criterion. In order$ to facilitate the identification six types of particular preference functions have been proposed (Table 2).

Linear preference function with linear preference and indifference area (type 3) and level preference function (type 4) are chosen for the selection of eco-efficient development strategy problem. Both functions are chosen based on the nature of criteria. The PROMETHEE with linear and level function method is assumed to be tailored to the nature of the criteria. For instance, linear preference function was chosen as one of the functions because it is best suited for quantitative criteria such as criterion $\mathrm{C} 1$ (cost). However, level preference function is best suited for qualitative criteria such as criterion C2 (social impact, economic impact, environmental impact). In addition, the level function works well in small numbers of different levels, such as the five-point impact scale used in this study.

Preference function of PROMETHEE is a function used to define deviations between alternatives for each criterion. In this paper, the definitions of preference functions are presented to fulfill the requirement of PROMETHEE algorithm that

Table 2. Types of generalized criteria $(P(d)$ : Preference function).

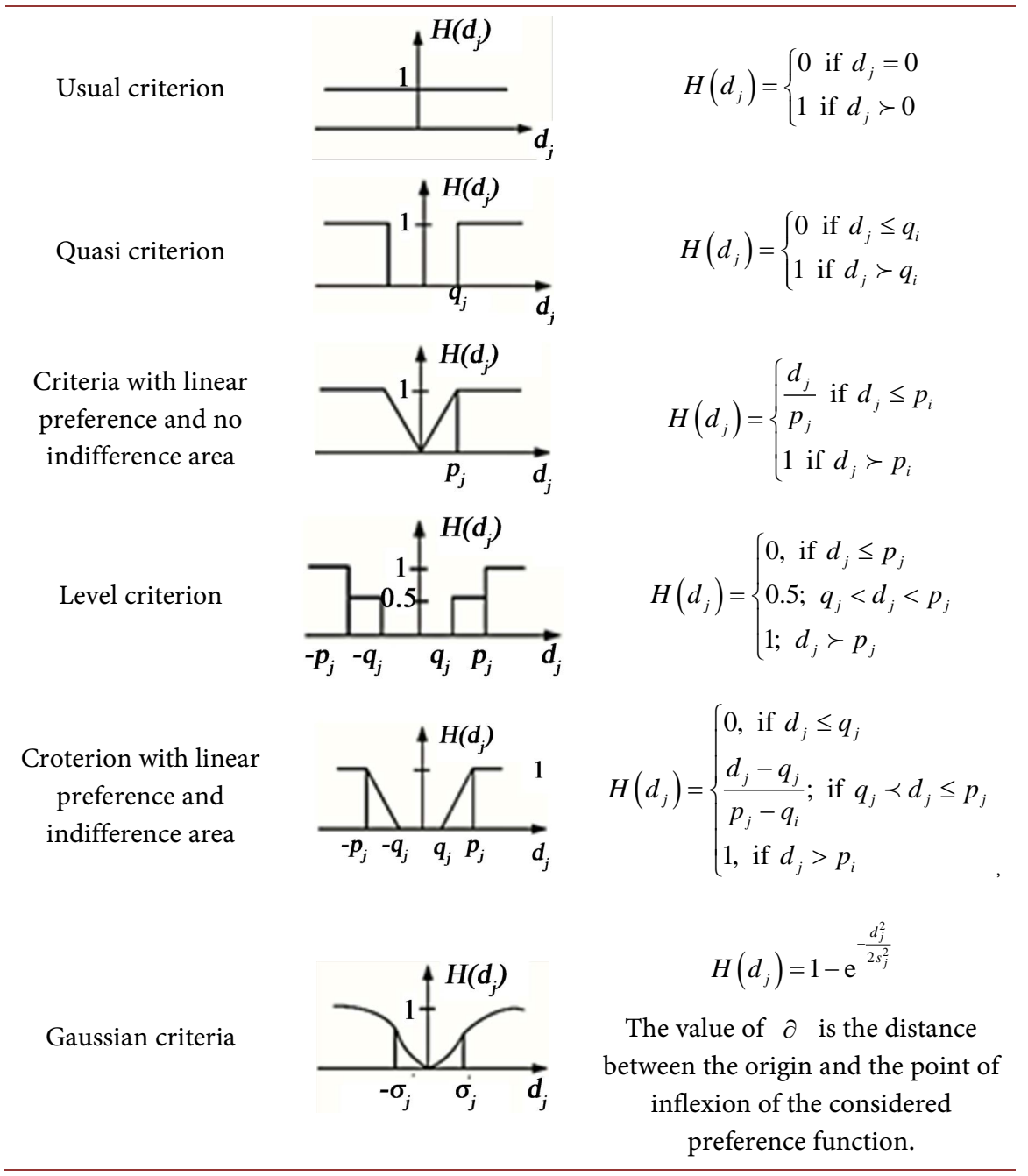


will be implemented to a case study. With reference to Step 5, three preference functions are employed as defined below:

Définition 1: Type I: Usual criteria function is defined as

$$
p(x)=\left\{\begin{array}{l}
0, \text { for } x \leq 0 \\
1, \text { for } x>0
\end{array}\right.
$$

where, where $x$ represents the deviation between two alternatives.

In type 1 , indifference only occurs when $f(a)=f(b)$. It is used when the decision-makers cannot allocate importance for the differences between criteria values and only seem to know the formula "the more the better".

Définition 2 Type III: Criterion with linear preference function is defined as

$$
p(x)=\left\{\begin{array}{l}
0, \quad x<0 \\
\frac{x}{m}, \quad 0 \leq x \geq m \\
1, \quad x>m
\end{array}\right.
$$

The intensity of preference increases linearly and becomes strict on point $\mathrm{m}$. Parameter $m$ is arbitrary and needs to be defined.

Definition 3: Type IV: Level criterion function is defined as

$$
p(x)=\left\{\begin{array}{l}
0, \text { for } x<q \\
\frac{1}{2}, \text { for } q \leq x \leq q+p \\
1, \text { for } x>q+p
\end{array}\right.
$$

Indifference over the interval, $-q \leq x \leq q$.

When a preference function has been associated with each criterion by the decision-maker, all comparisons between all pairs of actions can be made for all criteria.

Step 6 Determine the multi-criteria preference index (Equation (11)).

$$
\pi(a, b)=\sum_{j=1}^{k} P(a, b) w_{j}
$$

where,

- $w_{j}>0$ are the weights associated with each criterion, and

- the symbol $p(a, b)$ shows that the degree of $a$ is preferred to $b$ over all the criteria(Equation (12))

$$
\pi(a, b) \approx\left\{\begin{array}{l}
0, \text { implies a weak preference of } a \text { over } b \\
1, \text { implies a strong preference of } a \text { over } b
\end{array}\right.
$$

Step 7 Obtain the preference order

Here, the ranking can be made either partially or completely. Partial ranking can be obtained using PROMETHEE I, and in case complete ranking is needed, then the computation must proceed to one more step in PROMETHEE II.

a) Ranking the actions by partial ranking (PROMETHEE I)

Each alternative, $a$, is facing $n-1$ other alternatives in $A$. Hence, we define the following two outranking flows:

$\left(\phi^{+}\right)$: the positive outranking flow: 


$$
\phi^{+}(a)=\frac{1}{n-1} \sum_{b \in A} \pi(a, b)
$$

The positive outranking flow expresses how an alternative, $a$, is outranking all the others. It is its power, its outranking character. The higher $\phi^{+}(a)$ the better the alternative $\phi^{-}(a)$ the negative outranking flow:

$$
\phi^{-}(a)=\frac{1}{n-1} \sum_{b \in A} \pi(b, a)
$$

The negative outranking flow expresses how an alternative, $a$, is outranked by all the others. It is its weakness, its outranked character. The lower the, $\phi^{-}(a)$, better the alternative.

\section{The PROMETHEE I Partial Ranking}

The preference relation and partial ranking are derived as follows:

$$
\begin{aligned}
& a P^{+} b:\left\{\begin{array}{l}
P, \text { if and only if } \phi^{+}(a) \succ \phi^{+}(b) ; \forall a, b \in A \\
I, \text { if and only if } \phi^{+}(a)=\phi^{+}(b) ; \forall a, b \in A
\end{array}\right. \\
& a P^{-} b:\left\{\begin{array}{l}
P, \text { if and only if } \phi^{-}(a) \prec \phi^{-}(b) ; \forall a, b \in A \\
I, \text { if and only if } \phi^{-}(a) \succ \phi^{-}(b) ; \forall a, b \in A
\end{array}\right.
\end{aligned}
$$

However, not all alternatives are comparable. Thus, we need to calculate the net outranking flow in the following step.

b) Ranking the actions by a complete ranking (PROMETHEE II).

The complete rankings of alternatives can avoid incomparability

$$
\phi(a)=\phi^{+}(a)-\phi^{-}(a)
$$

where $\phi(a)$ denotes the net outranking flow for each alternative. The preference relations are as follows:

- $a$ outranks of $b$ ( $a p^{(\text {II) }} b$ if and only if $\phi(a) \succ \phi(b), \forall a, b \in A$;

- $a$ indifférent of $b\left(a I^{(\mathrm{II})} b\right.$ if and only if $\phi(a)=\phi(b), \forall a, b \in A$.

It is worth noting that all the alternatives are able to be compared based on the values of $\phi(a)$.

The highest values of $\phi(a)$ denote the most preferred alternative. In these series of computational procedures, most of the steps are fixed except Step 5. In this step, it is an arbitrary where the choice of preference functions depends very much on the characteristics of criteria and also the preference of decision-makers. Attention is paid to the choice of types of preference functions as it may affect the final net outranking values.

\section{Results and Discussions}

Our first sustainable development strategy for the city of Douala is the expropriation of all surrounding constructions located within the security perimeter of all gas stations and vice versa. Estimates of the cost of putting in place emergency response systems as well as "do nothing" were also made. In the process of estimating the cost of displacing and relocating the households, consideration was given to the quality (standing) of each building. A depreciation rate rate of 1 
percent was considered for all houses. For the gas stations, the cost estimation took into consideration the category of the station (Table 3 ).

Similar estimates were made for putting in place an emergency response plan. Key costing items included human and financial resources. The social, economic and environmental impacts of each of the actions were evaluated by experts. The overall results are presented in Table 4.

The information above (Table 3) was used was keyed into PROMETHEE GAIA software, together with the cost data that was collected from the field for computational purpose.

\subsection{Promethee Rankings}

The ranking of the alternatives is arranged in descending order of net flow value.

Table 3. Estimated cost of expropriation by category of inventoried service stations.

\begin{tabular}{ccccc}
\hline No. & Category & Frequency & Unit Cost (FCFA) & Total cost (FCFA) \\
\hline 1 & GRADE1 & 10 & $803,941,440$ & 8.039 .414 .400 \\
2 & GRADE2 & 34 & $1,004,926,800$ & 34.167 .511 .200 \\
3 & GRADE3 & 107 & $1,205,912,160$ & 129.032 .601 .120 \\
& & Total Cost & & 171.239 .526 .720
\end{tabular}

Table 4. Performance rating of the stations.

\begin{tabular}{|c|c|c|c|c|c|c|}
\hline \multirow{2}{*}{ Criteria } & \multirow{2}{*}{ Actions } & \multicolumn{5}{|c|}{ Experts } \\
\hline & & E1 & E2 & E3 & E4 & E5 \\
\hline \multirow{4}{*}{$\begin{array}{c}\text { Cost (FCFA) } \\
\left(\times 10^{9}\right)\end{array}$} & “Do Nothing” (A1) & 30 & 30 & 30 & 30 & 30 \\
\hline & Relocation of inhabitants (A2) & 2000 & 2000 & 2000 & 2000 & 2000 \\
\hline & Relocation of gas stations (A3) & 172 & 172 & 172 & 172 & 172 \\
\hline & Emergency Response Plan (A4) & 0.0245 & 0.0245 & 0.0245 & 0.0245 & 0.0245 \\
\hline \multirow{4}{*}{ Social Impact } & "Do Nothing" (A1) & 2 & 2 & 2 & 2 & 2 \\
\hline & Relocation of inhabitants (A2) & 1 & 1 & 1 & 1 & 1 \\
\hline & Relocation of gas stations (A3) & 2 & 2 & 2 & 2 & 2 \\
\hline & Emergency Response Plan (A4) & 5 & 5 & 5 & 5 & 5 \\
\hline \multirow{4}{*}{$\begin{array}{c}\text { Environmental } \\
\text { Impact }\end{array}$} & “Do Nothing” (A1) & 1 & 1 & 1 & 1 & 1 \\
\hline & Relocation of inhabitants (A2) & 1 & 1 & 1 & 1 & 1 \\
\hline & Relocation of gas stations (A3) & 2 & 2 & 2 & 2 & 2 \\
\hline & Emergency Response Plan (A4) & 4 & 4 & 4 & 4 & 4 \\
\hline \multirow{4}{*}{$\begin{array}{c}\text { Economic } \\
\text { Impact }\end{array}$} & “Do Nothing” (A1) & 3 & 3 & 3 & 3 & 3 \\
\hline & Relocation of inhabitants (A2) & 1 & 1 & 1 & 1 & 1 \\
\hline & Relocation of gas stations (A3) & 2 & 2 & 2 & 2 & 2 \\
\hline & Emergency Response Plan (A4) & 4 & 4 & 4 & 4 & 4 \\
\hline
\end{tabular}

$1 \mathrm{FCFA}=578 \mathrm{USD}$ 
The best alternative is the one having the highest net flow value, $\phi(a)$. By using both PROMETHEE I (partial) and II (complete ranking) method, alternative A4 (Emergency response plan) is selected as the best alternative (Figure 3).

While the PROMETHEE II complete ranking is easier to explain it is also less informative as the differences between $\mathrm{Phi}+$ and $\mathrm{Phi}-$ scores are not visible anymore. Incomparability in the PROMETHEE I ranking is interesting because it emphasizes actions that are difficult to compare and thus helps the decision-maker to focus on these difficult cases.

Both Phi+ and Phi- can be used to rank the actions. However they don't always provide exactly the same ranking. Indeed because of the conflicting aspect of a multicriteria problem it is not always easy to compare two actions: one can be much better on one subset of criteria and the other can be much better on another subset of criteria. In such cases and according to the preference parameters defined by the decision-maker different ways of evaluation (such as Phi+ and Phi-) can lead to different rankings. Hence, the PROMETHEE Diamond (Figure 4) was used as an alternative two-dimensional joint representation of both PROMETHEE I and II rankings to confirm the results above.

The square corresponds to the (Phi+, Phi-) plane where each action is represented by a point. The plane is angled $45^{\circ}$ so that the vertical dimension gives the Phi net flow. Phi+ scores increase from the left to the top corner and Phi- scores increase from the left to the bottom corner.

For each action, a cone is drawn from the action position in the plane.

As the strategy A4 cone overlaps all the other ones this action is preferred to all the other ones in the PROMETHEE I partial ranking. On the contrary, the lowest level cones corresponding to alternative A2 indicate incomparability. An

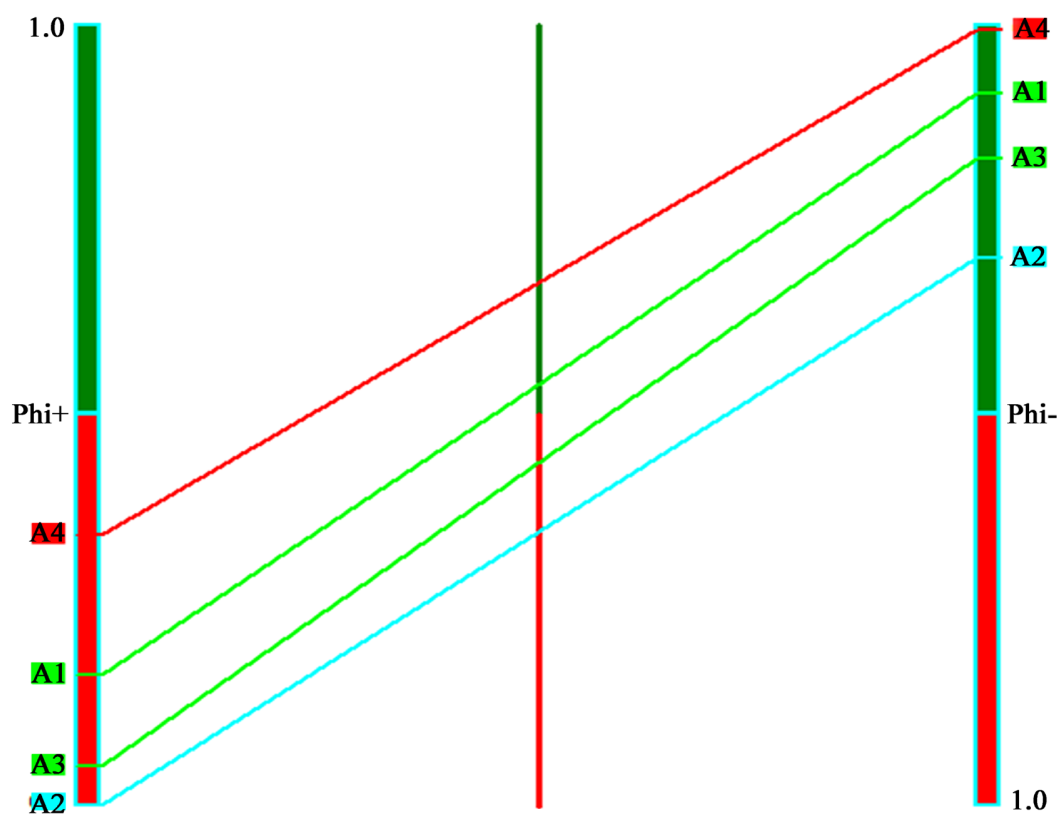

(a)

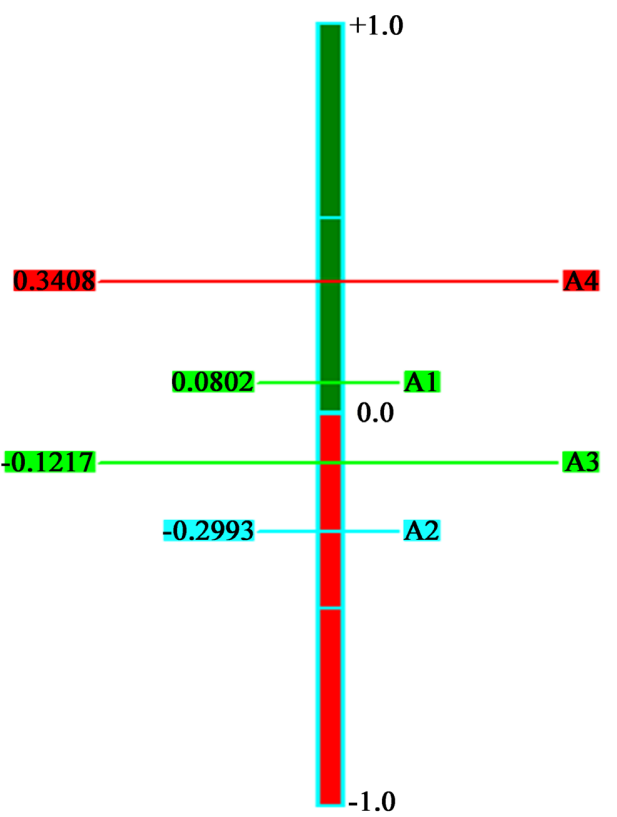

(b)

Figure 3. PROMETHEE rankings. (a) PROMETHEE I; (b) PROMETHEE II. 


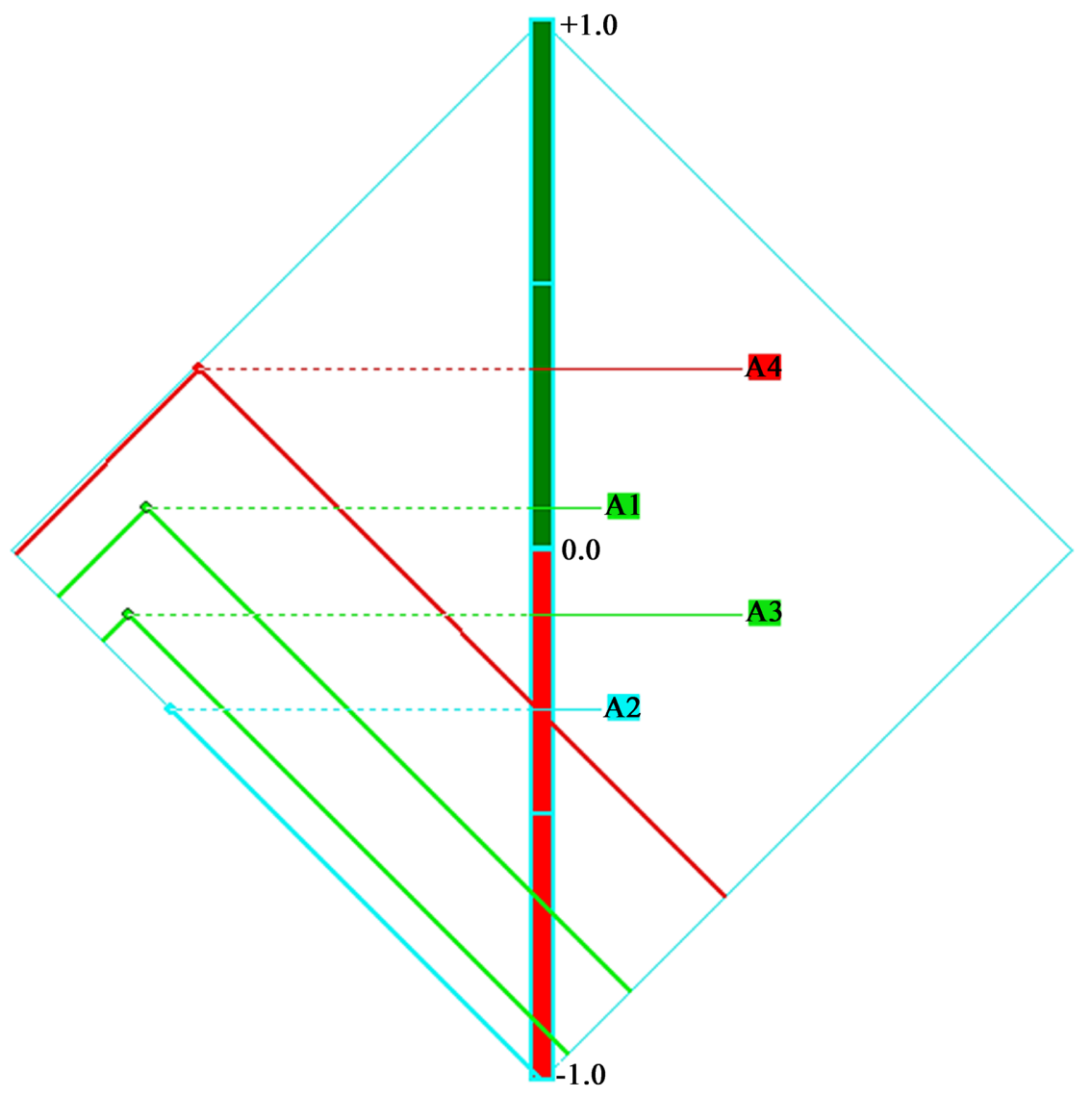

Figure 4. PROMETHEE Diamond.

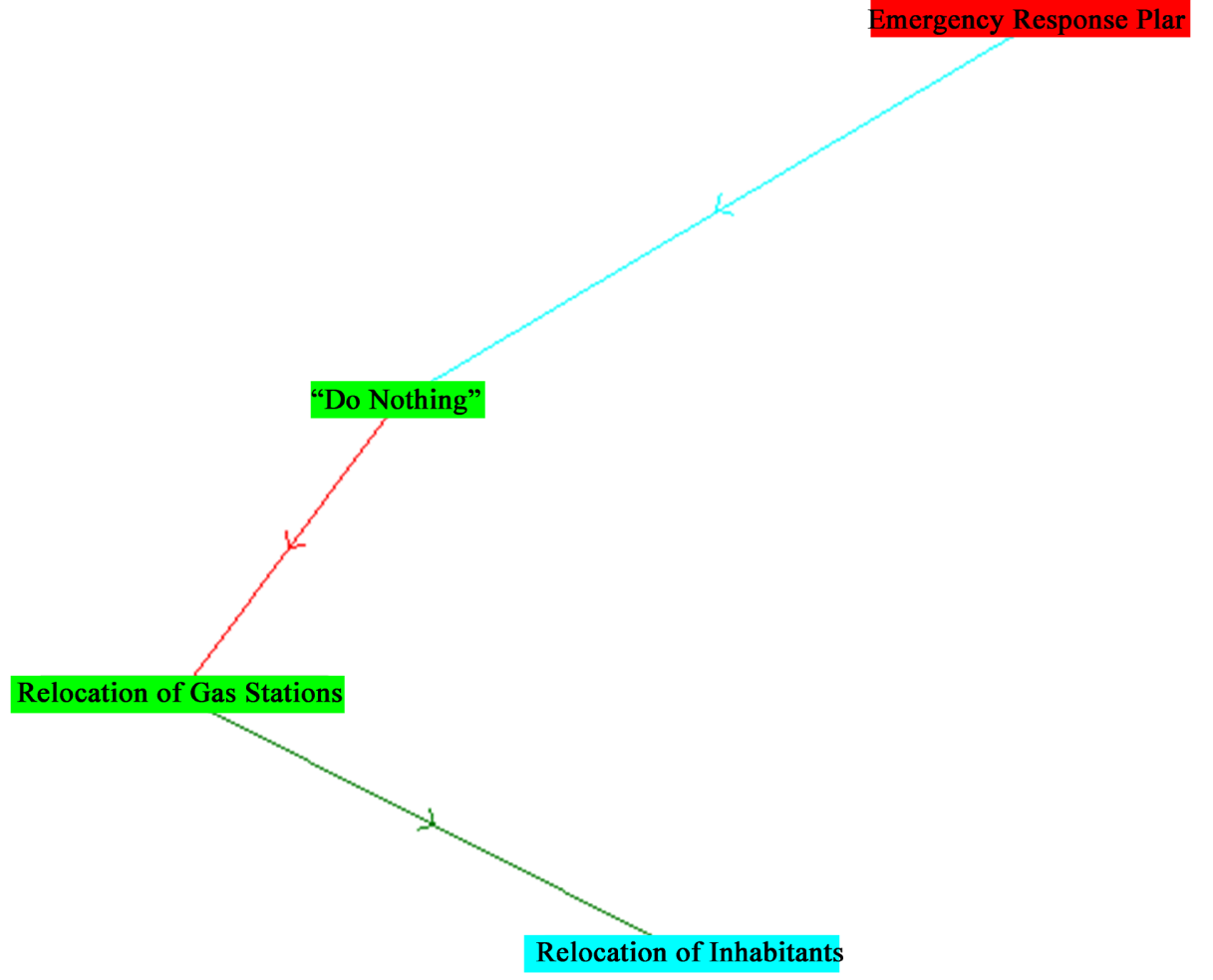

Figure 5. PROMETHEE II network in Visual PROMETHEE. 
advantage of the PROMETHEE Diamond is that it is easy to visualize the proximity between Phi+ and Phi- scores globally. A PROMETHEE network (Figure 5) further demonstrate

We inferred from the above figures that alternative A4 is ranked as the first preference followed by $\mathrm{A} 1$. The ranking order of preference of the alternatives is obtained as $\mathrm{A} 4>\mathrm{A} 1>\mathrm{A} 3>\mathrm{A} 2$, where " $>$ " shows "more preferred than". It can be concluded that the putting in place of an emergency response plan is the most preferred eco-efficient development strategy. A disaggregated view of the PROMETHEE II complete ranking, PROMETHEE rainbow (Figure 6) shows that the actions are displayed from left to right according.

For each action, the stacked slices show the components of the action net flow. For instance:

- Emergency response plan exhibits no negative slices as all criteria contribute positively to its net flow score. This action presents no weaknesses with respect to the other actions. The larger blue slice indicates that cost is the most important feature of this action. Its Phi score is positive.

- Relocation of gas stations has the very small slices. It has both weaknesses and disadvantages even if these are relatively small. It is quite average. Its Phi score is close to zero.

- Relocation of inhabitants is more of a mixed bag with serious environmental impacts.

\subsection{Determination of Positive and Negative Outranking Flows of Each Alternative}

Equation (8) is used to calculate these two flows. Leaving flow and entering flow

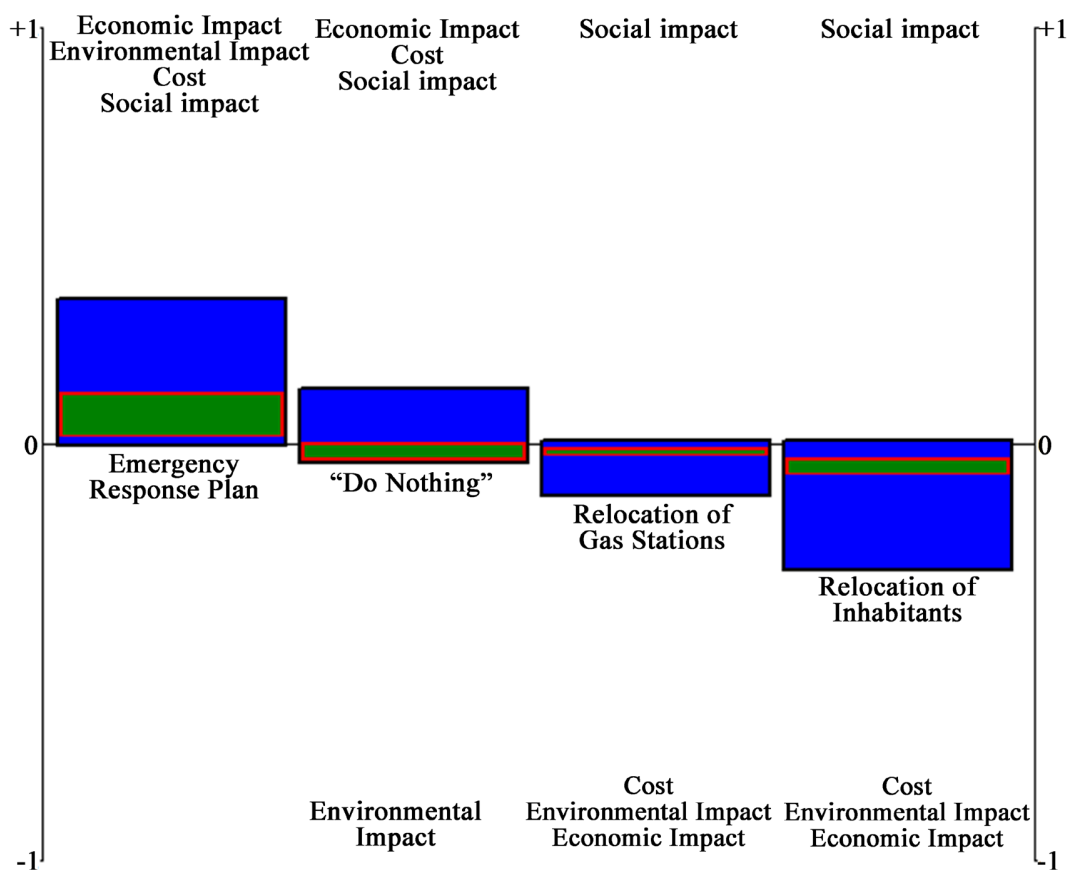

Figure 6. PROMETHEE Rainbow. 
of alternatives and the results are as follows (Table 5):

a) Leaving flow and entering flow of alternatives: Positive outranking flow (leaving flow) shows the degree of the supplier dominated other suppliers. In contrast, negative outranking flow (entering flow) shows the degree of the alternative dominated by other alternatives. b) Determine the net outranking flow (PROMETHEE II) for each alternative. Net flow values are calculated to avoid incomparability. Equation (9) is used to complete the calculation of net outranking flow. It is presented in Table 6.

To understand the relationship between alternatives and criteria, the analysis of GAIA (Graphical Analysis for Interactive Assistance) is made. With a representation value of $100 \%$, the relationship between suppliers and criteria is depicted in Figure 7.

The above screenshot shows the U-V plane. It contains three types of information:

- Actions are represented by points.

- Criteria are represented by axes.

- The weighing of the criteria and the PROMETHEE II ranking are represented by the decision axis.

In Visual PROMETHEE three dimensions are computed:

- $\mathrm{U}$ is the first principal component, and contains the maximum possible quantity of information.

- $\mathrm{V}$ is the second principal component, providing the maximum additional information orthogonal to U.

In practice, the 2D GAIA analysis is reliable when the quality level is above or close to $70 \%$. We can identify four different types of profiles:

- The "do nothing" alternative is on its own.

- Emergency response plan is on its own, and

Table 5. PROMETHEE I flow.

\begin{tabular}{|c|c|c|c|c|}
\hline Rank & Development Strategy & Phi & Phi+ & Phi- \\
\hline 1 & Emergency Response & 0.3408 & 0.3466 & 0.0059 \\
\hline 2 & "Do Nothing" & 0.0802 & 0.1677 & 0.0875 \\
\hline 3 & Relocation of Gas & -0.1217 & 0.0500 & 0.1717 \\
\hline 4 & Relocation of & -0.2993 & 0.0000 & 0.2993 \\
\hline
\end{tabular}

Table 6. Net flow value of the alternatives.

\begin{tabular}{|l|r|r|}
\hline \hline \multicolumn{1}{|c|}{ Strategy } & & Net Flow \\
\hline & & Total: \\
\hline “Do Nothing” & & 0.0802 \\
\hline Relocation of I... & & -0.2993 \\
\hline elocation of G... & $\square$ & -0.1217 \\
\hline Emergency Re... & & 0.3408 \\
\hline
\end{tabular}




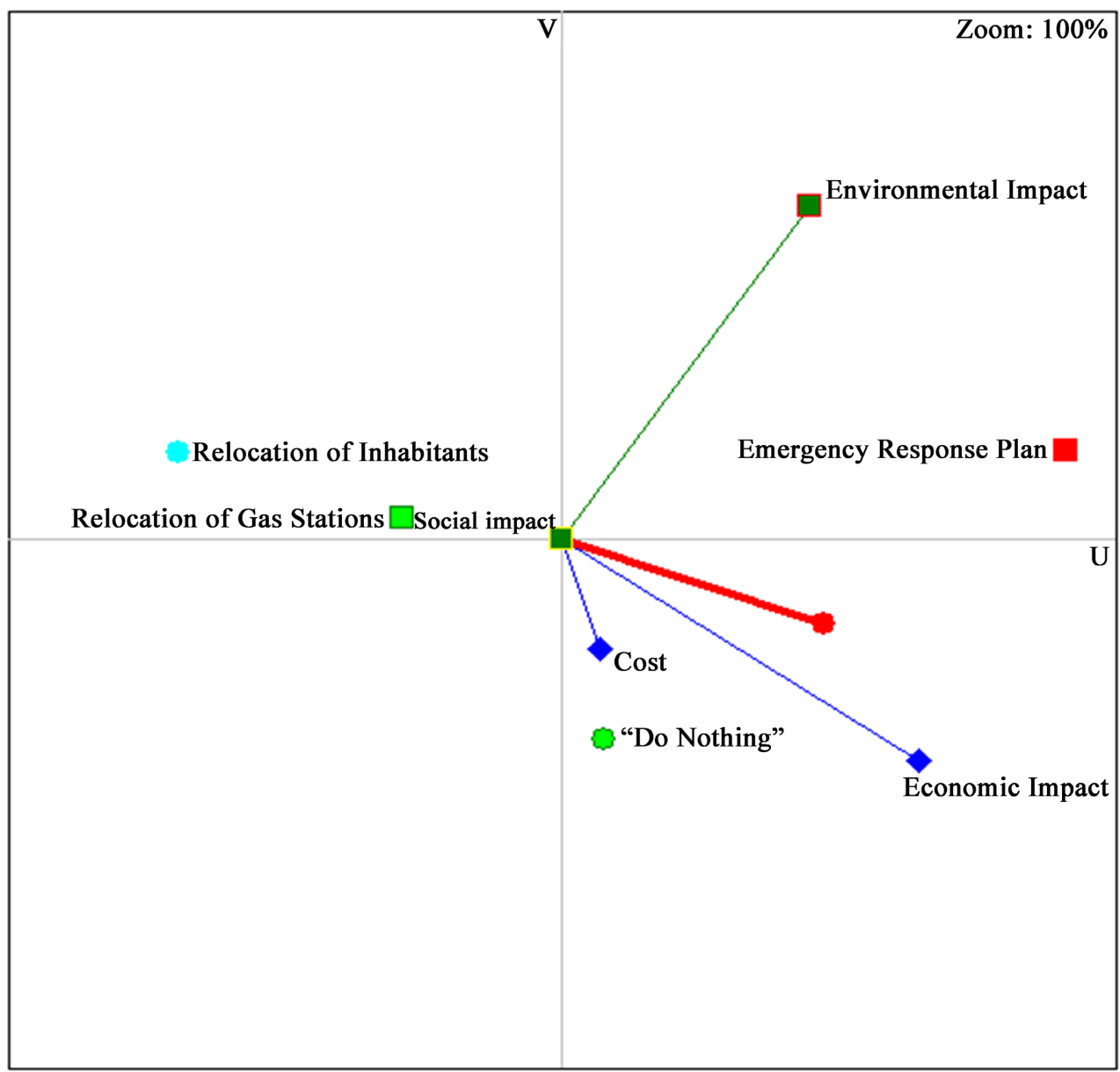

Figure 7. GAIA visual analysis.

- Relocation of gas stations and inhabitants are together. They are quite similar actions.

It can be seen that there are three groups of criteria, which can be identified as \{Cost, Economic impact\}, \{Environmental impact\}, and \{Social impact\}. These three sets seem to be independent from each other, and therefore, there is no strong conflict between the criteria.

It is often difficult to get a robust result due to the variability in relative importance of a given criterion. In response to this issue, an interactive tool called walking weights is used to check the sensitivity of the result. For example, the relative importance of criterion C2 is increased by $34 \%$; thus, a new result is shown in Figure 8.

We infer from the figure that the result does not have an impact on the firstranked alternative. However, a slight inconsistency in ranking can be seen for other three alternatives. The upper part is a bar chart showing the PROMETHEE II Complete Ranking. The lower part is a bar chart showing the weights of the criteria. The slider allows to change the weight of the selected criteria and to see the impact on the Visual PROMETHEE analysis. All opened windows are automatically updated. 


\subsection{Sensitivity Analysis}

To perform sensitivity with respect to a criterion in a hierarchy means to vary the priority of that node, maintaining the same relative proportion of the other nodes with respect to the goal, and seeing how the outcome changes. A more precise and thorough weight stability analysis can be done using the Visual Stability Intervals. The screenshot below (Figure 9) shows the visual stability analysis for
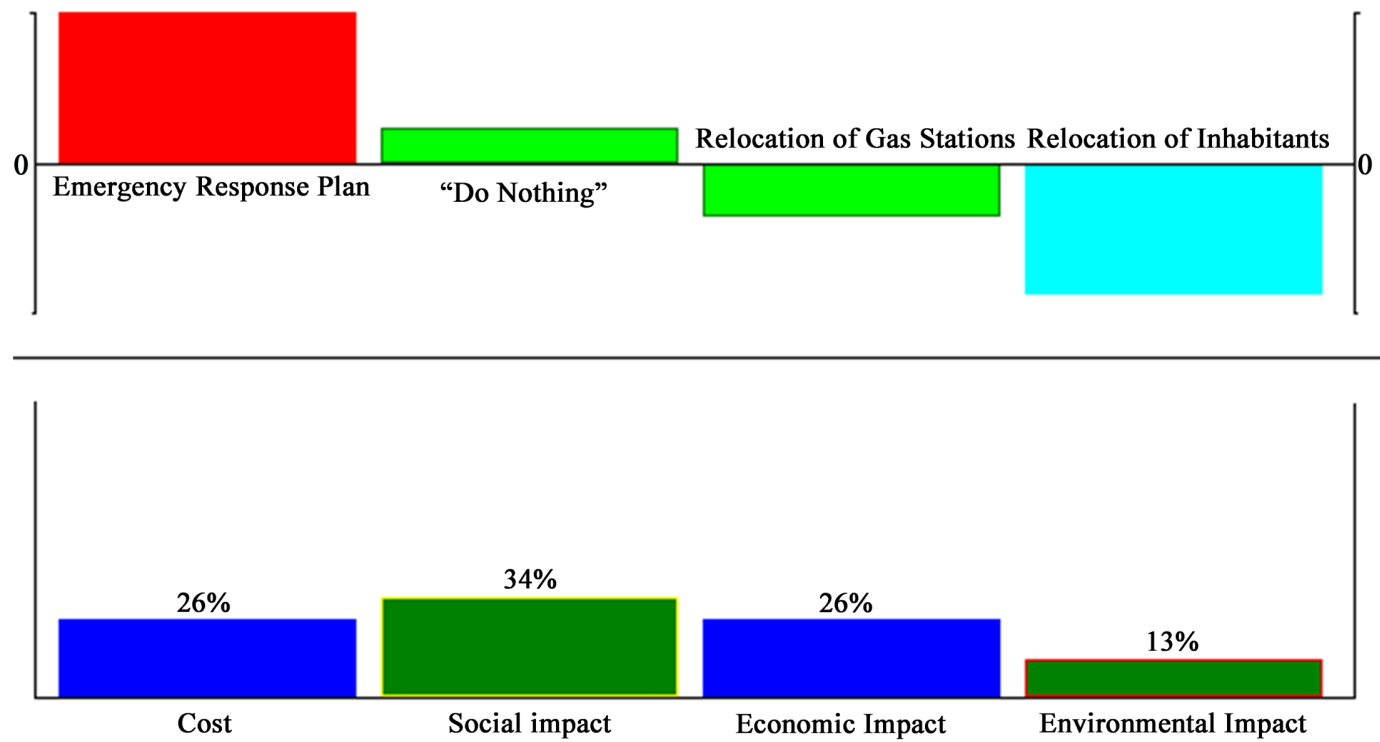

Figure 8. Walking weights.

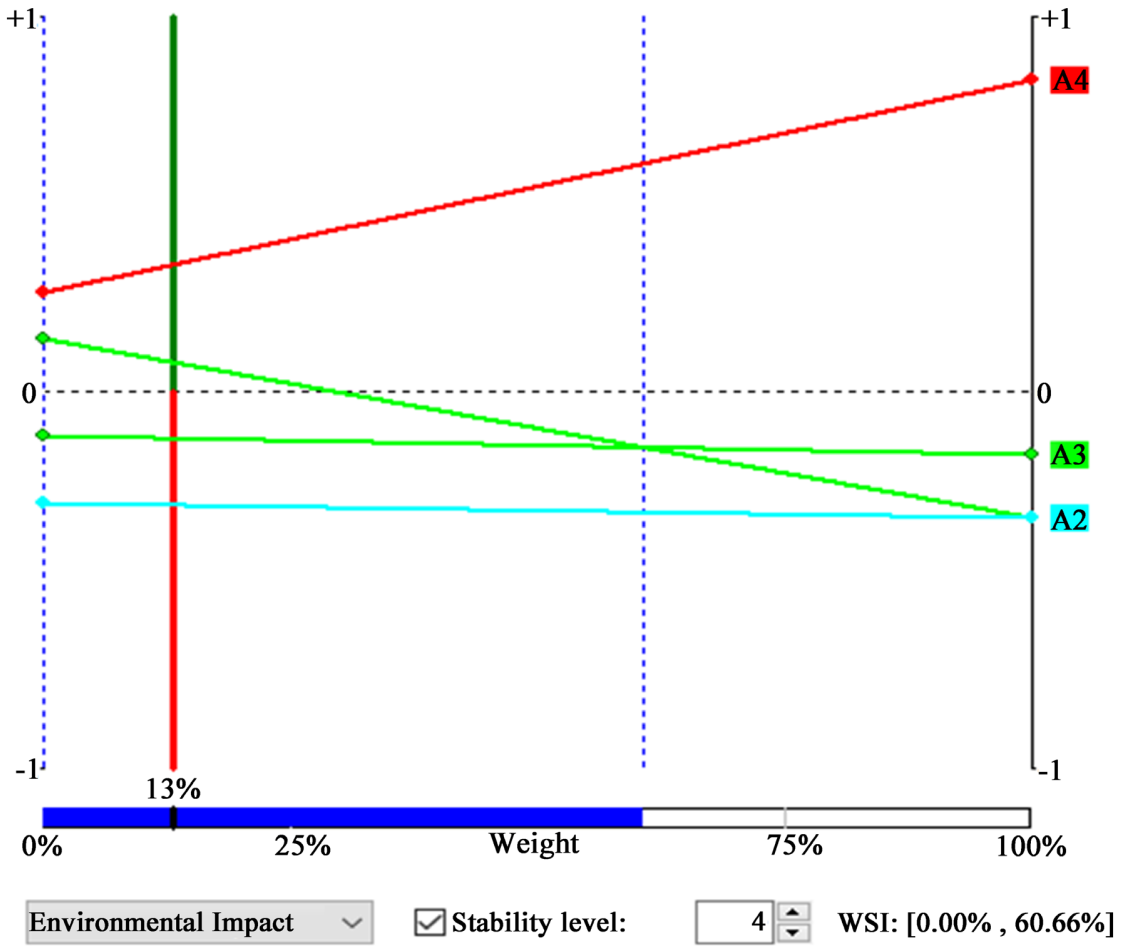

Figure 9. Visual stability analysis for criterion, Environmental impact. 
criterion "Environmental impact".

The horizontal axis is the weight of the criterion from $0 \%$ to $100 \%$. The vertical axis is the PROMETHEE net flow. For each active action, a line is drawn that shows how the net values change when the weight of the criterion is modified. In this case, it can be seen that action A4 (Emergency response plan) is at the top of the PROMETHEE II ranking for a wide range of weights. Modification of the weight of the criterion by half a percent does not cause a change in order. Based on the graph, we also deduce which changes will occur in the order in the case of changes out of stability intervals.

\section{Conclusions}

This paper has proposed the preference in selecting the eco-efficient development strategy in a human-inhabited industrial ecosystem. Different types of preference functions have been used in the implementation. The first net outflows and preference order are obtained using the usual criterion preference function, which is considered the simplest function. The second net outflows and preference order are obtained using the combination of linear preference function and level preference functions. Both of these functions are chosen based on the nature of criteria.

It can be seen that strategy A4 is consistently ranked as the first choice of development strategies. Contrarily, strategy A2 has the weakest performance for both preference functions. Furthermore, the net flow values of the entire alternative are analyzed and compared. The net flow (performance) values are used to see the effectiveness and efficiency of the strategies.

The PROMETHEE is one of the MCDM methods that is based on outranking. This method comprises many steps and choices of preference function as one of the significant steps. Many pieces of literature acknowledged that there are at least six types of preference functions in PROMETHEE. However, the effect of type of preference functions on the final preference order is not fully discussed. This paper has investigated this issue where the usual function, linear function and level function were used as the preference functions of PROMETHEE. This investigation was implemented to the case study of selecting an optimal eco-efficent development strategy in which four alternatives, five decision-makers and four criteria were the main structures of this MCDM method. It is found that the effect of these functions on the final preference order is not significant.

However, this study has some limitations, particularly in the choice of preference functions, its arithmetic operations and also the comparative analysis used. The choice of preference functions is limited to the three functions. Other preference functions or a modified preference function of PROMETHEE could be investigated in future research. The final preference order of this present study was obtained using subtraction operation which sometimes looks very straightforward. Other arithmetic operations such as division combined with the concept of distance perhaps shed light on future research. 


\section{Conflicts of Interest}

The authors declare no conflicts of interest regarding the publication of this paper.

\section{References}

[1] Albadvi, A., Chaharsooghi, S.K. and Esfahanipour, A. (2007) Decision Making in Stock Trading: An Application of PROMETHEE. European Journal of Operational Research, 177, 673-683. https://doi.org/10.1016/j.ejor.2005.11.022

[2] Abdel-malak F.F., Issa, U.H., Miky, Y.H. and Osman, E.A. (2017) Applying Decision-Making Techniques to Civil Engineering Projects. Beni-Suef University Journal of Basic and Applied Sciences, 6, 326-331.

https://doi.org/10.1016/j.bjbas.2017.05.004

[3] Batambock, S., Ndoh, I., Bitondo, D. and Waffo, A. (2021) Auditing the Siting of Petrol Stations in the City of Douala, Cameroon: Do They Fulfill the Necessary Regulatory Requirements? Advances in Science, Technology and Engineering Systems Journal, 6, 493-500. https://doi.org/10.25046/aj060154

[4] Behzadian, M., Kazemzadeh, R.B., Albadvi, A. and Aghdasi, M. (2010) PROMETHEE: A Comprehensive Literature Review on Methodologies and Applications. European Journal of Operational Research, 200, 198-215.

https://doi.org/10.1016/j.ejor.2009.01.021

[5] Brans, J.P. and Vincke, P. (1985) A Preference Ranking Organisation Method: The PROMETHEE Method for MCDM. Management Science, 31, 647-656.

https://doi.org/10.1287/mnsc.31.6.647

[6] Chandrakar, R. and Limje, S. (2018) A Hybrid of QFD and AHP-TOPSIS for Durg Dumping Waste Projects. Journal of Project Management, 3, 143-150.

http://www.growingscience.com/jpm/Vol3/jpm_2018_8.pdf https://doi.org/10.5267/j.jpm.2018.2.003

[7] Chattopadhyay, J., Dutta, B.K. and Vaze, K.K. (2014) Development of New Correlations for Improved Integrity Assessment of Pipes and Pipe Bends. Nuclear Engineering and Design, 269, 108-115. https://doi.org/10.1016/j.nucengdes.2013.08.015

[8] Koenig, D. (2011) Multiple Actors and Contested Terrains: Strategies of Pro-Poor Action in Contemporary Urban Restructuring. Journal of Developing Societies, 27, 327-353. https://doi.org/10.1177/0169796X1102700405

[9] Kowalski, K., Stagl, S., Madlener, R. and Omann, I. (2009) Sustainable Energy Futures: Methodological Challenges in Combining Scenarios and Participatory Multi-Criteria Analysis. European Journal of Operational Research, 197, 1063-1074. https://doi.org/10.1016/j.ejor.2007.12.049

[10] Marzouk, M. and Abdelakder, E. (2019) On the Use of Multi-Criteria Decision Making Methods for Minimizing Environmental Emissions in Construction Projects. Decision Science Letters, 8, 373-392. https://doi.org/10.5267/j.dsl.2019.6.002 http://www.growingscience.com/dsl/Vol8/dsl_2019_16.pdf

[11] Mitra, S., Mulligan, J., Schilling, J., Harper, J., Vivekananda, J. and Krause, L. (2017) Developing Risk or Resilience? Effects of Slum Upgrading on the Social Contract and Social Cohesion in Kibera, Nairobi. Environment and Urbanization, 29, 103-122. https://doi.org/10.1177/0956247816689218

[12] Polat, G. (2016) Subcontractor Selection Using the Integration of the AHP and PROMETHEE Methods. Journal of Civil Engineering and Management, 22, 1042-1054. https://journals.vgtu.lt/index.php/JCEM/article/view/1960/1576 
https://doi.org/10.3846/13923730.2014.948910

[13] Qin, X.S., Huang, G.H., Chakma, A. and Nie, X.H. (2008) A MCDM-Based Expert System for Climate-Change Impact Assessment and Adaptation Planning. A Case Study for the Georgia Basin, Canada. Expert Systems with Applications, 34, 2164-2179. https://doi.org/10.1016/j.eswa.2007.02.024

[14] Roghanian, E. and Alipour, M. (2014) A Fuzzy Model for Achieving Lean Attributes for Competitive Advantages Development Using AHPQFD-PROMETHEE. Journal of Industrial Engineering International, 10, Article No. 68. https://doi.org/10.1007/s40092-014-0068-4

[15] Saaty, T.L. (1980) The Analytic Hierarchy Process. McGraw-Hill, New York. https://doi.org/10.21236/ADA214804

[16] Saaty, T.L. (2010) Principia Mathematica Decernendi: Mathematical Principles of Decision Making. RWS Publications, Pittsburgh.

[17] Sri Krishna, S., Sri Nivasulu Readdy, A. and Vani, S. (2014) A New Car Selection in the Market Using TOPSIS. International Journal of Engineering Research and General Science, 2, 177-181. http://ijergs.org/files/documents/A-NEW20.pdf

[18] Shanian, A. and Savadogo, O. (2006) TOPSIS Multiple-Criteria Decision Support Analysis for Material Selection of Metallic Bipolar Plates for Polymer Electrolyte Fuel Cell. Journal of Power Sources, 159, 1095-1104.

https://doi.org/10.1016/j.jpowsour.2005.12.092

[19] Tuzkaya, G., Gulsun, B., Kahraman, C. and Ozgen, D. (2010) An Integrated Fuzzy Multi-Criteria Decision Making Methodology for Material Handling Equipment Selection Problem and an Application. Expert Systems with Applications, 37, 2853-2863. https://doi.org/10.1016/j.eswa.2009.09.004

[20] Vasic, G. (2018) Application of Multi Criteria Analysis in the Design of Energy Policy: Space and Water Heating in Households-City Novi Sad, Serbia. Energy Policy, 113, 410-419. https://doi.org/10.1016/j.enpol.2017.11.025

[21] Watson, V. (2014) African Urban Fantasies: Dreams or Nightmares? Environment and Urbanization, 26, 215-231. https://doi.org/10.1177/0956247813513705

[22] Yazdani, M. (2015) New Intuitionistic Fuzzy Approach with Multi-Objective Optimisation on the Basis of Ratio Analysis Method. International Journal of Business and Systems Research, 9, 355-374. https://doi.org/10.1504/IJBSR.2015.072584

[23] Zopounidis, C. and Pardalos, P. (2010) Handbook of Multicriteria Analysis. Springer, Berlin. https://doi.org/10.1007/978-3-540-92828-7 